\title{
Evaluating Trends and Outcomes of Spinal Deformity Surgery in Cerebral Palsy Patients
}

\author{
EMMANUEL N. MENGA, MD,${ }^{1}$ DAVID N. BERNSTEIN, MBA, MA,${ }^{1}$ CAROLINE THIRUKUMARAN, PHD, ${ }^{1}$ \\ SEKINAT K. MCCORMICK, MD, ${ }^{2}$ PAUL T. RUBERY, MD, ${ }^{1}$ ADDISU MESFIN, MD $^{1}$ \\ ${ }^{I}$ Department of Orthopaedic Surgery, University of Rochester, Rochester, New York, ${ }^{2}$ Department of Orthopaedic Surgery, University of Texas Health San \\ Antonio, San Antonio, Texas
}

\begin{abstract}
Background: There is a paucity of literature examining surgical trends and outcomes in both child and adult cerebral palsy (CP) patients. We aimed to evaluate surgical trends, complications, length of stay, and charges for spinal deformity surgery in CP patients.

Methods: Using the Nationwide Inpatient Sample (NIS) from 2001 to 2013, patients with CP scoliosis who underwent spinal fusion surgery were identified. Patient characteristics and comorbidities were recorded. Trends in spinal fusion approaches were grouped as anterior (ASF), posterior (PSF), or combined anterior-posterior (ASF/PSF). Complication rates, length of stay, and charges for each approach were analyzed. Bivariate analyses using adjusted Wald tests and multivariate analyses using linear (logarithmic transformation) and logistic regressions were performed.

Results: Of the 5191 adult CP patients who underwent spinal fusion the majority underwent PSF (86.5\%), followed by the ASF/PSF approach (9.3\%). The rate of PSF for cerebral palsy patients with spinal deformity increased significantly per 1 million people in the US population $(0.90$ to $1.30 ; P=.048)$. Complication rate, hospital length of stay, and charges were higher for patients undergoing ASF/PSF $(P<.05)$. The overall complication rate for all surgical approaches was $25.7 \%$. Patient comorbidities and combined ASF/PSF increased the odds of complication. Combined $\mathrm{ASF} / \mathrm{PSF}$ was also associated with an increased length of stay and charges.

Conclusion: Combined ASF/PSF in patients with CP accounted for only $9.3 \%$ of surgical cases but was associated with the longest hospital stay, highest charges, and increased complications. Further scrutiny of the surgical indications and preoperative risk stratification should be undertaken to minimize complications, reduce length of stay, and decrease charges for CP patients undergoing spinal fusion.
\end{abstract}

Level of Evidence: IV

\section{Complications}

Keywords: Nationwide Inpatient Sample (NIS), spinal deformity, cerebral palsy, trends, complications, hospital charges, length of stay

\section{INTRODUCTION}

Surgical correction of scoliosis for patients with cerebral palsy (CP) scoliosis, a form of neuromuscular scoliosis, is associated with increased morbidity in comparison with idiopathic scoliosis. ${ }^{1-5}$ Anterior spinal fusion (ASF) for treatment of spinal deformity, with or without a posterior spinal fusion (PSF) approach, is also associated with high complication rates. ${ }^{1,6,7}$

Recent use of pedicle screw instrumentation allows for 3-column fixation via a posterior-only surgical approach. Multiple studies have demonstrated acceptable correction of scoliosis deformity in patients with neuromuscular scoliosis using an all-posterior surgical approach, including patients with large and rigid curves. ${ }^{8-10}$ The addition of an anterior approach, particularly with 3-column pedicle screw fixation, is reserved for patients with very stiff or rigid spinal curves, young patients at risk for crankshaft phenomenon, patients with dysplastic posterior elements, and large spinal curves requiring anterior release or shortening of the anterior column to achieve the deformity correction goals.

To date, a number of studies have compared the outcomes and morbidities associated with singlestage surgery, combined anterior and posterior spinal fusion (combined ASF/PSF) surgery, and staged ASF and PSF surgery in younger patients with neuromuscular scoliosis. ${ }^{11-14}$ However, there is a paucity of literature reporting a comparison of the complication rates, discharge destination, charges, 
and length of hospital stay for all patients, including adults, with CP undergoing ASF versus PSF versus combined ASF/PSF. In the current $\mathrm{CP}$ literature for all age ranges, Tsirikos et $\mathrm{al}^{9}$ reported increased duration of intensive care unit stays and length of hospitalization for patients with $\mathrm{CP}$ undergoing ASF/PSF versus patients undergoing PSF for spinal deformity. However, the study did not report on the outcomes for patients undergoing ASF, which is important given the added aorta-related risk associated with anterior spinal surgical correction of scoliosis. $^{15}$

A more robust analysis of all surgical spinal fusion approaches used to address spinal deformity in all $\mathrm{CP}$ patients - not just young $\mathrm{CP}$ patients - is warranted in order for surgeons to have a better understanding of what factors drive poor outcomes so that preoperative optimization can occur, and frank risk-benefit shared decision-making discussions can be had. Thus, this study aims to evaluate trends in spinal fusion surgery and associated complication rates, hospital charges, and length of stay for all patients with $\mathrm{CP}$ undergoing corrective spinal fusion surgery.

\section{MATERIALS AND METHODS}

\section{Data Source}

Developed for the Healthcare Cost and Utilization Project under the auspice of the Agency for Healthcare Research and Quality, the Nationwide Inpatient Sample (NIS) is the largest all-payer inpatient healthcare database in the United States. ${ }^{16}$ Each year's dataset contains more than 7 million hospital stays (20\% national cross-sectional sample), and when weighted using validated measures, can estimate more than 35 million hospitalizations nationally. ${ }^{16}$ All variables (eg, US hospital region) used were defined by NIS. ${ }^{16}$ The data is publicly available and deidentified; thus, institutional review board approval is not required for its use in this study.

\section{Study Cohort}

The study period of interest was from 2001 to 2013. Using International Classification of Diseases, Ninth Revision, Clinical Modification (ICD-9-CM) diagnosis and procedure codes, patients with $\mathrm{CP}$ undergoing spinal fusion surgery were identified in the following manner. Patients were considered for inclusion and were identified as having $\mathrm{CP}$ using the
ICD-9-CM code: 343.9. Patients with confirmed CP were then queried to determine which patients underwent spinal fusion surgery (ICD-9-CM procedure codes: 81.04 to 81.09 ). The study sample was then refined further by retaining only discharges with Medical Severity-Diagnosis Related Groups between 453 and 460 or 496 and $498^{17}$ and those patients with the Healthcare Cost and Utilization Project's Clinical Classification Software for Procedures of 158 .

In total, 1091 patients met our study inclusion criteria. Surgical approach was grouped as ASF, PSF, or combined ASF/PSF. The sample was then weighted using validated NIS discharge weights to estimate a national sample. The final sample used for all analyses consisted of 5191 patients with CP who underwent spinal fusion surgery from 2001 to 2013.

\section{Statistical Analysis}

The weighted number of patients undergoing each surgical approach was recorded for each year. The weighted value was then divided by the US population, as determined by the US Census, ${ }^{18}$ to determine the number of surgeries per 1 million people. Linear regression analysis was used to evaluate if there was any significant change in the number of procedures per 1 million people from 2001 to 2013.

Baseline descriptive statistics were calculated and compared between CP patients undergoing anterior, posterior, or combined spinal fusion surgical approaches prior to surgery using adjusted Wald tests. The variables compared were age, sex, race, comorbidities (paralysis, neurological disorders, fluid and electrolyte disorders, chronic pulmonary disease, iron-deficiency anemia), payor, hospital bed-size, hospital location and teaching status, hospital region, and hospital control. For the following variables, the percentage of the patient sample in each was compared across the different surgical approaches: age (less than 21 years versus at or above 21 years), women, white, use of government insurance (Medicare or Medicaid), large hospital bed-size, urban teaching hospital, southern region of the United States, and private hospital control.

In addition, outcomes were calculated and compared between $\mathrm{CP}$ patients undergoing anterior, posterior, or combined spinal fusion surgical approaches prior to surgery using adjusted Wald 
Table 1. Rates of spinal deformity surgery by approach on patients with cerebral palsy per 1 million in the US population, 2001 to 2013 . Data are presented as mean (range).

\begin{tabular}{lccc}
\hline Year & ASF & PSF & ASF/PSF \\
\hline 2001 & $0.017(-0.017$ to 0.053$)$ & $0.90(0.54-1.26)$ & $0.17(0.042-0.29)$ \\
2002 & $0.13(0.038-0.21)$ & $0.89(0.48-1.29)$ & $0.40(0.097-0.70)$ \\
2003 & $0.052(-0.0072-0.11)$ & $0.80(0.46-1.14)$ & $0.19(0.076-0.30)$ \\
2004 & $0.018(-0.017-0.051)$ & $1.05(0.65-1.45)$ & $0.092(0.018-0.17)$ \\
2005 & $0.12(0.017-0.21)$ & $1.41(0.83-2.01)$ & $0.19(0.068-0.31)$ \\
2006 & $0.074(0.0087-0.14)$ & $1.05(0.62-1.47)$ & $0.034(-0.013$ to 0.080$)$ \\
2007 & $0.016(-0.015$ to 0.046$)$ & $0.98(0.61-1.35)$ & $0.093(0.0053-0.18)$ \\
2008 & $0.076(-0.0031$ to 0.16$)$ & $1.27(0.66-1.88)$ & $0.072(0.0085-0.14)$ \\
2009 & $0.049(-0.0069$ to 0.10$)$ & $1.35(0.87-1.84)$ & $0.085(0.010-0.16)$ \\
2010 & $0.045(-0.0065$ to 0.10$)$ & $1.25(0.72-1.78)$ & $0.11(0.028-0.19)$ \\
2011 & $0.061(0.0018-0.12)$ & $1.27(0.96-1.58)$ & $0.029(-0.011$ to 0.067$)$ \\
2012 & $0.064(0.0011-0.13)$ & $1.30(1.02-1.57)$ & $0.064(0.0038-0.12)$ \\
2013 & $0.016(-0.015$ to 0.047$)$ & 4490 & $0.11(0.028-0.19)$ \\
Raw total (weighted) & 217 & .048 & 484 \\
$P$ value, trend & .941 & .349 \\
\hline
\end{tabular}

ASF indicates anterior spinal fusion; PSF, posterior spinal fusion; ASF/PSF, combined ASF and PSF.

tests. For the following outcome variables, the percentage of the patient sample in each was compared across the different surgical approaches: at least one complication, at least one pulmonary complication, discharge to home, and complications (cardiac, neurologic, durotomy, gastrointestinal, renal, venous thromboembolism, wound). The mean lengths of stay (days) and hospitalization charges (adjusted to 2013 dollars) were also compared across surgical approaches.

Multivariate logistic regression analysis was conducted to determine which patient, hospital, and systems-based factors were independently associated with complications, while a linear multivariate regression with logarithmic transformation was conducted to determine which patient, hospital, and systems-based factors were independently associated with hospital length of stay and hospitalization charges. Complications were a categorical outcome reported as "yes/no." Both the length of stay and charges per stay were continuous outcome variables with length of stay reported in days and charges per stay reported in 2013 dollars.

For all analyses, significance was set at $P<.05$ a priori.

\section{RESULTS}

From 2001 to 2013, the number of CP patients undergoing a PSF per 1 million people in the US population significantly increased from 0.90 to 1.30 $(P=.048)$ (Table 1$)$. There was no change in the number of $\mathrm{CP}$ patients undergoing a combined $\mathrm{ASF} / \mathrm{PSF}(P=.349)$ or $\mathrm{ASF}(P=.941)$. A visual representation of the surgical trends from 2001 to 2013 for all approaches can be seen in the Figure.
Of the 5191 patients meeting our inclusion criteria, a majority were women $(52 \%)$ and white $(52 \%)$, and just under three-quarters of all patients were younger than 21 years of age (73\%) (Table 2). A PSF was the most common surgery (87\%). Those undergoing an ASF were significantly older than patients undergoing a PSF or combined ASF/PSF (anterior: 31 years versus posterior: 22 years versus combined: 23 years; $P<.01$ ). In addition, a significantly higher percentage of patients undergoing a combined ASF/PSF had paralysis, as defined by the NIS database (combined: $100 \%$ versus anterior: $98 \%$ versus posterior: $97 \% ; P<.01$ ) and fluid and electrolyte disorders (combined: $18 \%$ versus posterior: $14 \%$ versus anterior: $4.3 \%$; $P<.01)$ comorbidities. Patients undergoing surgery at urban teaching hospitals were more likely to undergo a PSF (posterior: $88 \%$ versus combined: $81 \%$ versus anterior: $68 \% ; P=.01$ ).

Patients undergoing a combined ASF/PSF had the highest rate of at least 1 complication $(38 \%$, 95\% confidence interval $[\mathrm{CI}]: 30-47 ; \mathrm{p}<.01$ ) (Table 3). Additionally, the combined ASF/PSF had the highest average length of stay (12 days, 95\% CI: 9.8$14 ; P<.01)$ and hospitalization charges $(\$ 80,373$, $95 \%$ CI: $\$ 67,255$ - $\$ 93,492 ; P=.02)$. Complications varied by surgical approach, with cardiac complications being more common in PSF and durotomy, renal, and venous thromboembolism complications being more common when a combined ASF/PSF was used.

Using multivariate logistic regression analysis, a combined ASF/PSF (odds ratio [OR]: $2.85,95 \%$ CI: 1.01-8.03), iron deficiency anemia (OR: 1.61, 95\% CI: 1.01-2.59), coagulation disorder (OR: 3.43, 95\% 


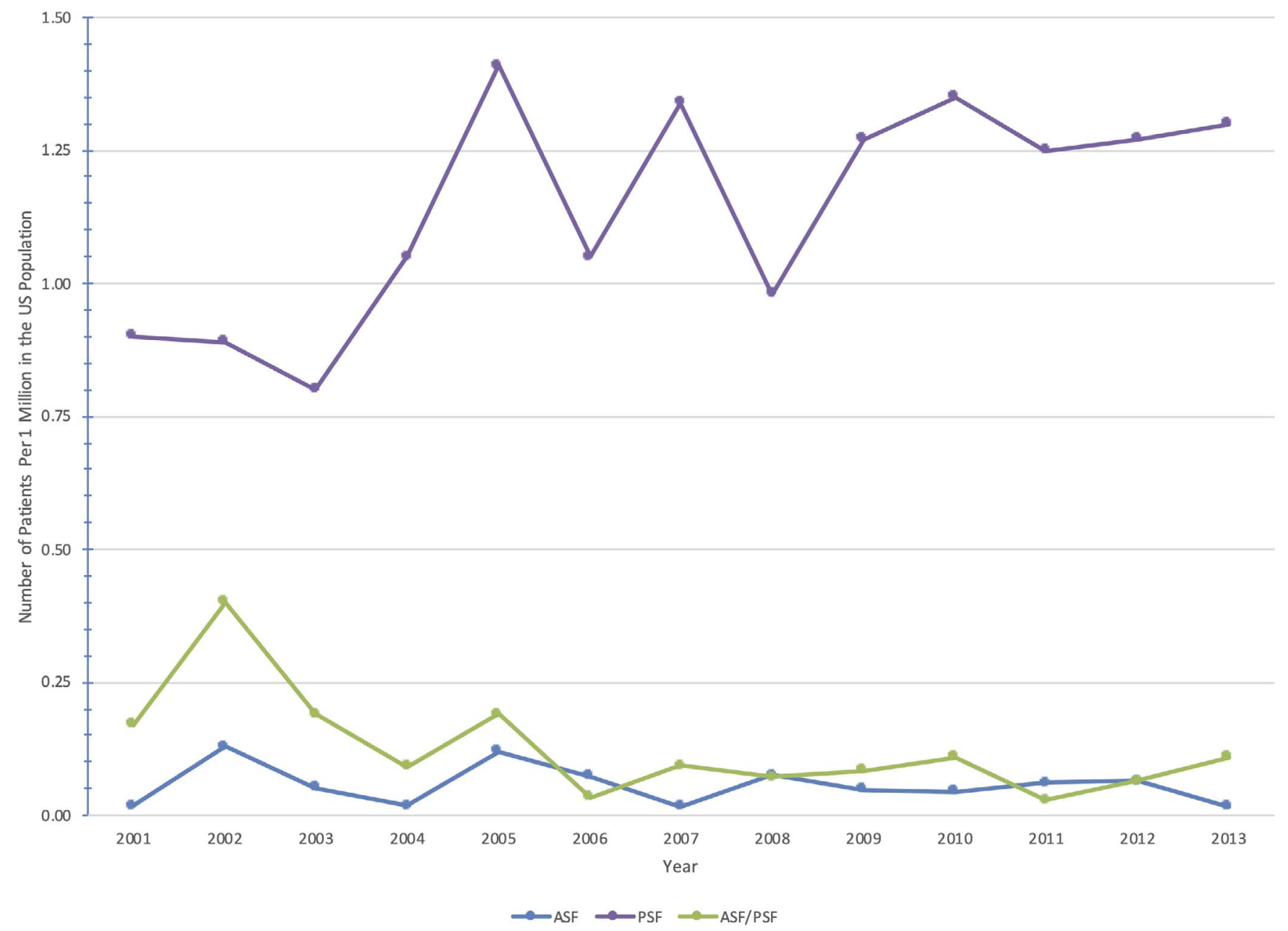

Figure. An illustration of the rates of spinal deformity surgery by approach on patients with cerebral palsy per 1 million in the US population, 2001 to 2013.

CI: 1.98-5.94), fluid and electrolyte disorder (OR: 2.59, 95\% CI: 1.65-4.08), neurologic disorder (OR: $1.62,95 \%$ CI: $1.15-2.28)$, and pulmonary circulation disorder (OR: 22.46, 95\% CI: 1.09-46.28) were significantly associated with increased risk of postoperative complication (Table 4).
Using multivariable linear regression with logarithmic transformation, combined ASF/PSF $(\beta=0.18,95 \%$ CI: $0.03-0.33)$, in-hospital complication $(\beta=0.29,95 \% \mathrm{CI}$ : $0.23-0.35)$, drug abuse $(\beta=0.60,95 \%$ CI: 0.37-0.84), lymphoma $(\beta=0.73$, 95\% CI: 0.45-1.01), fluid and electrolyte disorder

Table 2. Comparison of patient and hospital characteristics by surgical approach for spine deformity in the setting of cerebral palsy, 2001 to 2013 . Data are percentages presented as mean (SE).

\begin{tabular}{|c|c|c|c|c|c|}
\hline Characteristic & Total, $n=5191$ & $\mathrm{ASF}, n=217$ & PSF, $n=4490$ & ASF $/$ PSF, $n=484$ & $P$ Value \\
\hline Age, $<21$ years & $72.46(2.14)$ & $42.98(7.75)$ & $74.47(2.15)$ & $67.04(5.64)$ & $<.01$ \\
\hline Female & $51.90(1.60)$ & $47.60(7.31)$ & $52.63(1.78)$ & $47.02(5.06)$ & .51 \\
\hline Race, white & $51.85(2.69)$ & $58.83(7.15)$ & $50.99(2.79)$ & $56.69(5.62)$ & .37 \\
\hline Comorbidities & $2.17(0.04)$ & $2.28(0.15)$ & $2.17(0.04)$ & $2.19(0.12)$ & .74 \\
\hline Paralysis & $97.52(0.68)$ & $97.87(2.12)$ & $97.24(0.78)$ & 100.00 & $<.01$ \\
\hline Neurological disorders & $39.79(1.56)$ & $33.16(6.63)$ & $40.87(1.67)$ & $32.78(5.22)$ & .17 \\
\hline Fluid and electrolyte disorders & $14.10(1.10)$ & $4.32(2.94)$ & $14.13(1.15)$ & $18.17(3.79)$ & $<.01$ \\
\hline Chronic pulmonary disease & $14.15(1.16)$ & $15.78(5.39)$ & $14.08(1.19)$ & $14.07(3.40)$ & .95 \\
\hline Iron-deficiency anemias & $11.75(1.14)$ & $13.02(4.79)$ & $11.79(1.20)$ & $10.79(2.99)$ & .90 \\
\hline Payor, government-Medicare/Medicaid & $55.49(2.11)$ & $56.49(7.68)$ & $55.35(2.05)$ & $56.34(6.83)$ & .98 \\
\hline Hospital bed-size, large & $63.82(3.18)$ & $56.99(7.13)$ & $64.00(3.23)$ & $65.24(7.12)$ & .62 \\
\hline Hospital location and teaching, urban teaching & $86.44(1.10)$ & $68.08(6.66)$ & $87.94(1.15)$ & $80.82(4.55)$ & .01 \\
\hline Hospital region, South & $41.44(3.04)$ & $46.85(7.26)$ & $41.54(3.07)$ & $38.04(7.65)$ & .70 \\
\hline Hospital control, private & $47.31(2.83)$ & $49.77(7.59)$ & $48.66(2.89)$ & $33.65(6.75)$ & .08 \\
\hline
\end{tabular}

ASF indicates anterior spinal fusion; PSF, posterior spinal fusion; ASF/PSF, combined ASF and PSF. 
Table 3. Comparison of outcomes, including complications, discharge destination, length of stay, and hospitalization costs by surgical approach for spine deformity in the setting of cerebral palsy, 2001 to 2013.

\begin{tabular}{|c|c|c|c|c|c|}
\hline Outcome & Total, $n=5191$ & $\mathrm{ASF}, n=217$ & PSF, $n=4490$ & $\mathrm{ASF} / \mathrm{PSF}, n=484$ & $P$ Value \\
\hline \multicolumn{6}{|l|}{ Complication rate, $\%(95 \% \mathrm{CI})$} \\
\hline At least 1 complication & $25.73(22.88-28.81)$ & $16.47(8.43-29.71)$ & $24.84(21.94-27.99)$ & $38.19(30.17-46.90)$ & $<.01$ \\
\hline At least 1 pulmonary complication & $15.96(13.73-18.46)$ & $12.21(5.59-24.61)$ & $15.26(12.91-17.95)$ & $24.08(17.40-32.33)$ & .07 \\
\hline Discharge to home, $\%(95 \% \mathrm{CI})$ & $68.12(64.18-71.82)$ & $71.14(56.00-82.67)$ & $68.39(64.19-72.32)$ & $64.24(55.07-72.47)$ & .61 \\
\hline Length of stay, mean $(95 \% \mathrm{CI})$ & $7.41(7.01-7.80)$ & $7.09(5.14-9.04)$ & $6.96(6.62-7.30)$ & $11.67(9.83-13.52)$ & $<.01$ \\
\hline $\begin{array}{l}\text { Hospitalization charges (adjusted to } \\
2013 \text { dollars), mean }(95 \% \mathrm{CI})\end{array}$ & 63605 (59 553-67 657) & $55540(42$ 104-68 976) & 62150 (57 976-66 324) & 80373 (67 255-93 492) & .02 \\
\hline \multicolumn{6}{|c|}{ Complication details (univariate), \% (95\% CI) } \\
\hline At least 1 cardiac complication & $1.56(0.01-0.03)$ & $0.00(0.00-0.00)$ & $1.71(0.01-0.03)$ & $0.94(0.00-0.07)$ & $<.01$ \\
\hline At least 1 neurologic complication & $0.46(0.00-0.01)$ & $0.00(0.00-0.00)$ & $0.44(0.00-0.01)$ & $0.91(0.00-0.06)$ & .14 \\
\hline At least 1 durotomy & $0.65(0.00-0.01)$ & $0.00(0.00-0.00)$ & $0.64(0.00-0.01)$ & $1.03(0.00-0.07)$ & .02 \\
\hline At least 1 gastrointestinal complication & $6.13(0.05-0.08)$ & $8.14(0.03-0.20)$ & $5.67(0.04-0.07)$ & $9.55(0.05-0.16)$ & .35 \\
\hline At least 1 renal complication & $5.46(0.04-0.07)$ & $0.00(0.00-0.00)$ & $5.51(0.04-0.07)$ & $7.50(0.04-0.14)$ & $<.01$ \\
\hline $\begin{array}{l}\text { At least } 1 \text { venous thromboembolism } \\
\text { complication }\end{array}$ & $0.55(0.00-0.01)$ & $0.00(0.00-0.00)$ & $0.33(0.00-0.01)$ & $2.91(0.01-0.08)$ & .04 \\
\hline At least 1 wound complication & $1.45(0.01-0.03)$ & $2.17(0.00-0.14)$ & $1.27(0.01-0.02)$ & $2.77(0.01-0.07)$ & .44 \\
\hline
\end{tabular}

$\mathrm{CI}$ indicates confidence I=interval; ASF, anterior spinal fusion; PSF, posterior spinal fusion; ASF/PSF, combined ASF and PSF.

$(\beta=0.13,95 \% \quad C I: 0.07-0.19)$, and neurologic disorder $(\beta=0.09,95 \%$ CI: 0.05-0.13) were associated with an increased length of stay (Table 4). In contrast, patients at or above 21 years of age $(\beta=-0.09,95 \%$ CI: -0.17 to -0.01$)$ or with a "missing" race variable $(\beta=-0.08,95 \% \mathrm{CI}$ : -0.16 to -0.00 ) had decreased lengths of stay. Variables associated with increased hospitalization charges included: combined ASF/PSF $(\beta=0.28,95 \% \mathrm{CI}$ : 0.07-0.49), having a complication in the hospital $(\beta=0.26,95 \%$ CI: $0.19-0.34)$, procedures completed between 2006 to 2009 ( $\beta=0.39$, 95\% CI: 0.28 $0.51)$ or 2010 to 2013 ( $\beta=0.31,95 \%$ CI: $0.16-0.47)$, AIDS $(\beta=0.45,95 \%$ CI: $0.15-0.75)$, chronic blood loss anemia $(\beta=0.15,95 \% \mathrm{CI}: 0.01-0.29)$, coagulopathy $(\beta=0.14,95 \% \mathrm{CI}$ : 0.01-0.27), complicated diabetes $(\beta=0.34,95 \% \mathrm{CI}$ : 0.06-0.62), lymphoma $(\beta=1.00,95 \% \mathrm{CI}: 0.56-1.44)$, and neurological disorders $(\beta=0.10,95 \%$ CI: 0.03-0.16). Factors associated with decreased hospitalization charges included: patients at or above 21 years of age $(\beta=-0.20,95 \% \mathrm{CI}:-0.32$ to -0.09$)$, transfer from the same/another acute hospital $(\beta=-0.66,95 \%$ CI: -1.12 to -0.21$)$, hypertension $(\beta=-0.18,95 \%$ CI: -0.31 to -0.05$)$, and $\mathrm{CHF}(\beta=-0.39,95 \% \mathrm{CI}$ : -0.71 to -0.07$)$.

\section{DISCUSSION}

This study offers a comprehensive, national representative analysis of different surgical approaches and their effect on outcomes and charges in all patients with CP (instead of only pediatric patients) undergoing spinal deformity correction. This is novel, as a much larger portion of prior research has focused only on younger patients with CP. We show that only the PSF approach increased significantly per 1 million people in the US population from 2001 to 2013 (0.90-1.30; $P=.048)$. Further, our results indicate that although only $9.3 \%$ of patients in the study group underwent a combined $\mathrm{ASF} / \mathrm{PSF}$, this technique was associated with the longest hospital stays, highest hospital charges, and increased complications. Further, a number of comorbidities and patient characteristics, including neurological disorders, fluid and electrolyte disorders, patient age, and other factors (eg, perioperative complications), are associated with worse outcomes, longer length of stay, or higher charges depending on the surgical approach. Our findings, when taken altogether, suggest that further scrutiny of the preoperative risk stratification, indication for surgery, and optimization of modifiable risk factors may improve clinical and financial outcomes, especially in patients with $\mathrm{CP}$ undergoing a combined ASF/PSF.

Overall, we found a national complication rate of $26 \%$ for CP patients undergoing spinal fusion surgery for spinal deformity. Despite the broader age range in our study, consistent with these findings is a single-center study of 102 pediatric patients undergoing neuromuscular scoliosis surgery; they reported overall complication rate was $27 \%{ }^{19}$ Of note, however, only $26.5 \%$ of the patients in this study had CP. Nonetheless, it is plausible that patient outcomes across surgical intervention for neuromuscular scoliosis act similarly across diagnoses. Indeed, another study by Master et $\mathrm{al}^{20}$ analyzed 131 consecutive patients with neuromuscular scoliosis (majority had CP 
Table 4. Multivariate analyses for complications, length of stay, and cost per stay in adult patients undergoing surgery for spine deformity in the setting of cerebral palsy.

\begin{tabular}{|c|c|c|c|}
\hline & $\begin{array}{l}\text { Complications, } \\
\text { Odds Ratio } \\
\text { (95\% CI) }\end{array}$ & $\begin{array}{l}\text { Length of Stay, } \\
\beta \text { Estimate, } \\
\text { Log-Transformed } \\
(95 \% \text { CI })\end{array}$ & $\begin{array}{c}\text { Charges Per Stay } \\
\text { (2013 Adjusted USD), } \\
\beta \text { Estimate, } \\
\text { Log-Transformed } \\
(95 \% \text { CI })\end{array}$ \\
\hline Constant & $0.04(0.00-0.42)^{\mathrm{b}}$ & $1.74(1.43-2.06)^{\mathrm{c}}$ & $10.58(10.07-11.09)^{\mathrm{c}}$ \\
\hline \multicolumn{4}{|l|}{ Surgical approach } \\
\hline Anterior spinal fusion & Ref & Ref & Ref \\
\hline Posterior spinal fusion & $1.43(0.55-3.72)$ & $-0.04(-0.16$ to 0.09$)$ & $0.04(-0.15$ to 0.24$)$ \\
\hline Combined approaches & $2.85(1.01-8.03)^{\mathrm{a}}$ & $0.18(0.03-0.33)^{\mathrm{a}}$ & $0.28(0.07-0.49)^{\mathrm{b}}$ \\
\hline \multicolumn{4}{|l|}{ Complications } \\
\hline No & & Ref & Ref \\
\hline Yes & & $0.29(0.23-0.35)^{\mathrm{c}}$ & $0.26(0.19-0.34)^{\mathrm{c}}$ \\
\hline \multicolumn{4}{|l|}{ Age } \\
\hline$<21$ years & Ref & Ref & Ref \\
\hline$\geq 21$ years & $0.96(0.59-1.58)$ & $-0.09(-0.17 \text { to }-0.01)^{\mathrm{a}}$ & $-0.20(-0.32 \text { to }-0.09)^{\mathrm{c}}$ \\
\hline \multicolumn{4}{|c|}{ - } \\
\hline Male & Ref & Ref & Ref \\
\hline Female & $1.08(0.78-1.50)$ & $0.03(-0.02$ to 0.07$)$ & $-0.05(-0.11$ to 0.02$)$ \\
\hline \multicolumn{4}{|r|}{ 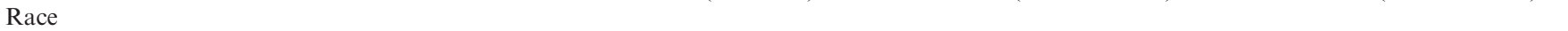 } \\
\hline Nonwhite & Ref & Ref & Ref \\
\hline White & $0.94(0.64-1.38)$ & $-0.05(-0.11$ to 0.01$)$ & $-0.09(-0.19$ to 0.01$)$ \\
\hline Missing & $1.21(0.70-2.10)$ & $-0.08(-0.16 \text { to } 0.00)^{\mathrm{a}}$ & $-0.13(-0.28$ to 0.02$)$ \\
\hline \multicolumn{4}{|l|}{ Primary payor } \\
\hline Government-Medicare/Medicaid & Ref & Ref & Ref \\
\hline Private & $0.97(0.70-1.34)$ & $-0.01(-0.06$ to 0.04$)$ & $0.05(-0.02$ to 0.12$)$ \\
\hline Self-pay, no charge, other & $0.71(0.30-1.65)$ & $-0.06(-0.20$ to 0.08$)$ & $-0.18(-0.37$ to 0.02$)$ \\
\hline \multicolumn{4}{|l|}{ Year } \\
\hline 2001 to 2005 & Ref & Ref & Ref \\
\hline 2006 to 2009 & $0.73(0.42-1.26)$ & $-0.03(-0.10$ to 0.04$)$ & $0.39(0.28-0.51)^{\mathrm{c}}$ \\
\hline 2010 to 2013 & $0.66(0.34-1.28)$ & $-0.07(-0.17$ to 0.02$)$ & $0.31(0.16-0.47)^{\mathrm{c}}$ \\
\hline \multicolumn{4}{|l|}{ Admission source } \\
\hline Not a transfer (Routine/emergency room) & Ref & Ref & Ref \\
\hline Transfer from same/another acute hospital & $3.21(0.11-97.65)$ & $0(-0.58$ to 0.58$)$ & $-0.66(-1.12 \text { to }-0.21)^{\mathrm{b}}$ \\
\hline Transfer from another heathcare facility & $1.63(0.29-9.20)$ & $-0.55(-1.14$ to 0.04$)$ & $-0.12(-0.52$ to 0.28$)$ \\
\hline \multicolumn{4}{|l|}{ Elixhauser's comorbidty algorithm } \\
\hline AIDS & $1.00(1.00-1.00)$ & $0.20(-0.46$ to 0.87$)$ & $0.45(0.15-0.75)^{\mathrm{b}}$ \\
\hline Alcohol abuse & $4.53(0.46-44.36)$ & $0.12(-0.19$ to 0.44$)$ & $-0.21(-0.78$ to 0.36$)$ \\
\hline Deficiency anemias & $1.61(1.01-2.59)^{\mathrm{a}}$ & $0.02(-0.05$ to 0.08$)$ & $-0.04(-0.15$ to 0.07$)$ \\
\hline Rheumatoid arthritis/collagen vascular diseases & $1.01(0.11-9.25)$ & $0.16(-0.06$ to 0.38$)$ & $0.13(-0.24$ to 0.49$)$ \\
\hline Chronic blood loss anemia & $2.93(0.80-10.71)$ & $0.08(-0.08$ to 0.25$)$ & $0.15(0.01-0.29)^{\mathrm{a}}$ \\
\hline Congestive heart failure & $1.00(1.00-1.00)$ & $0.16(-0.17$ to 0.49$)$ & $-0.39(-0.71 \text { to }-0.07)^{\mathrm{a}}$ \\
\hline Chronic pulmonary disease & $1.15(0.75-1.76)$ & $-0.01(-0.07$ to 0.05$)$ & $0.00(-0.11$ to 0.10$)$ \\
\hline Coagulopathy & $3.43(1.98-5.94)^{\mathrm{c}}$ & $0.09(0.00-0.18)$ & $0.14(0.01-0.27)^{\mathrm{a}}$ \\
\hline Depression & $1.05(0.38-2.88)$ & $-0.11(-0.24$ to 0.02$)$ & $0.01(-0.22$ to 0.23$)$ \\
\hline Diabetes, uncomplicated & $2.22(0.81-6.12)$ & $-0.06(-0.19$ to 0.08$)$ & $-0.26(-0.52$ to 0.01$)$ \\
\hline Diabetes, complicated & & $0.37(-0.13$ to 0.86$)$ & $0.34(0.06-0.62)^{\mathrm{a}}$ \\
\hline Drug abuse & & $0.60(0.37-0.84)^{\mathrm{c}}$ & $0.29(-0.06$ to 0.64$)$ \\
\hline Hypertension & $0.54(0.28-1.06)$ & $-0.02(-0.11$ to 0.06$)$ & $-0.18(-0.31 \text { to }-0.05)^{\mathrm{b}}$ \\
\hline Hypothyroidism & $1.03(0.39-2.72)$ & $0.06(-0.05$ to 0.18$)$ & $0.09(-0.09$ to 0.26$)$ \\
\hline Liver disease & $1.41(0.14-14.12)$ & $0.02(-0.24$ to 0.28$)$ & $-0.01(-0.64$ to 0.62$)$ \\
\hline Lymphoma & & $0.73(0.45-1.01)^{\mathrm{c}}$ & $1.00(0.56-1.44)^{\mathrm{c}}$ \\
\hline Fluid and electrolyte disorders & $2.59(1.65-4.08)^{\mathrm{c}}$ & $0.13(0.07-0.19)^{\mathrm{c}}$ & $0.06(-0.04$ to 0.16$)$ \\
\hline Neurological disorders & $1.62(1.15-2.28)^{\mathrm{b}}$ & $0.09(0.05-0.13)^{\mathrm{c}}$ & $0.10(0.03-0.16)^{\mathrm{b}}$ \\
\hline Obesity & $0.89(0.24-3.31)$ & $0.09(-0.07$ to 0.25$)$ & $0.07(-0.17$ to 0.31$)$ \\
\hline Paralysis & $0.82(0.33-2.00)$ & $-0.07(-0.18$ to 0.04$)$ & $-0.16(-0.34$ to 0.01$)$ \\
\hline Peripheral vascular disorders & & $0.02(-0.18$ to 0.21$)$ & $-0.05(-0.89$ to 0.79$)$ \\
\hline Psychoses & & $-0.04(-0.22$ to 0.14$)$ & $-0.06(-0.30$ to 0.18$)$ \\
\hline Pulmonary circulation disorders & $22.46(1.09-46.28)^{\mathrm{a}}$ & $0.14(-0.06$ to 0.34$)$ & $-0.11(-0.52$ to 0.30$)$ \\
\hline Renal failure & $0.98(0.11-8.98)$ & $-0.20(-0.48$ to 0.08$)$ & $0.01(-0.22$ to 0.25$)$ \\
\hline Valvular disease & $0.74(0.18-3.05)$ & $-0.01(-0.17$ to 0.15$)$ & $0.29(-0.01$ to 0.59$)$ \\
\hline Weight loss & $1.95(0.61-6.26)$ & $0.07(-0.11$ to 0.26$)$ & $0.08(-0.16$ to 0.32$)$ \\
\hline \multicolumn{4}{|l|}{ Hospital bed strength } \\
\hline Small & Ref & Ref & Ref \\
\hline Medium & $1.19(0.65-2.18)$ & $0.06(-0.07$ to 0.18$)$ & $0.00(-0.17$ to 0.18$)$ \\
\hline Large & $1.3(0.77-2.20)$ & $0.07(-0.05$ to 0.19$)$ & $-0.03(-0.17$ to 0.11$)$ \\
\hline \multicolumn{4}{|l|}{ Hospital ownership } \\
\hline Government & Ref & Ref & Ref \\
\hline Private & $1.23(0.57-2.65)$ & $0.07(-0.02$ to 0.16$)$ & $0.05(-0.12$ to 0.21$)$ \\
\hline Mixed & $0.64(0.27-1.55)$ & $0.1(-0.01$ to 0.21$)$ & $-0.04(-0.24$ to 0.16$)$ \\
\hline
\end{tabular}




\begin{tabular}{|c|c|c|c|}
\hline & $\begin{array}{c}\text { Complications, } \\
\text { Odds Ratio } \\
\text { (95\% CI) }\end{array}$ & $\begin{array}{c}\text { Length of Stay, } \\
\beta \text { Estimate, } \\
\text { Log-Transformed } \\
(95 \% \text { CI })\end{array}$ & $\begin{array}{c}\text { Charges Per Stay } \\
\text { (2013 Adjusted USD), } \\
\beta \text { Estimate, } \\
\text { Log-Transformed } \\
(95 \% \text { CI) }\end{array}$ \\
\hline \multicolumn{4}{|c|}{ Hospital location and teaching status } \\
\hline Rural & Ref & Ref & Ref \\
\hline Urban, nonteaching & $3.66(0.72-18.74)$ & $0.00(-0.20$ to 0.20$)$ & $0.13(-0.23$ to 0.49$)$ \\
\hline Urban, teaching & $4.64(0.92-23.44)$ & $0.09(-0.11$ to 0.28$)$ & $0.2(-0.15$ to 0.55$)$ \\
\hline \multicolumn{4}{|l|}{ Hospital region } \\
\hline Northeast & Ref & Ref & Ref \\
\hline Midwest & $0.95(0.48-1.87)$ & $0.06(-0.04$ to 0.16$)$ & $-0.06(-0.21$ to 0.09$)$ \\
\hline South & $0.87(0.50-1.49)$ & $0.01(-0.08$ to 0.10$)$ & $-0.04(-0.19$ to 0.11$)$ \\
\hline West & $1.05(0.56-1.97)$ & $0.06(-0.04$ to 0.16$)$ & $0.09(-0.09$ to 0.28$)$ \\
\hline
\end{tabular}

Ref indicates reference.

${ }^{\mathrm{a}} P<.05$.

${ }^{\mathrm{b}} P<.01$.

${ }^{\mathrm{c}} P<.001$.

[57\%]) at a single institution and found a similar rate of complications at $28 \%$. While consistent, this complication rate is quite high and warrants further exploration. It is possible that improved risk factor modification and/or optimization may benefit such patients undergoing surgical intervention.

In our analysis, we found that CP patients with pulmonary circulation disorders, as defined by NIS, had the largest increased odds of having a complication (OR: 7.39, 95\% CI: 1.27-43.03, $P<.05$ ). Prior work in patients with neuromuscular scoliosis undergoing surgery also suggested an association between pulmonary comorbidities and complication rates. ${ }^{19}$ Within the $\mathrm{CP}$ patient literature, a small study of 19 cases suggested that respiratory complications are very common, ${ }^{21}$ and within the neuromuscular scoliosis literature in general, respiratory complications have also been shown to be one of the most common complications. ${ }^{22}$ These reports are consistent with our findings of increased risk of complication in patients with $\mathrm{CP}$ and underlying pulmonary disorders. Thorough evaluation of preoperative pulmonary comorbidities may prove valuable in reducing the outcomes and complications associated with spinal fusion surgery in patients with CP. Indeed, involving a pulmonologist preoperatively may also be beneficial in trying to reduce postoperative issues.

In our study, numerous comorbidities were independently associated with an increased risk of complications. Prior research has demonstrated that $\mathrm{CP}$ patients with more than 2 comorbidities are at an increased risk of complications. ${ }^{21}$ Further, we found that those CP patients undergoing combined ASF/PSF had a higher risk of complications as reported by Bendon et al. ${ }^{21}$ Additionally, combined
ASF/PSF was also independently associated with increased length of stay and charges. These outcomes are likely intertwined, as patients who remain in the hospital longer likely have higher charges for treatment. However, it is important to note that our study population is a niche that is challenging to treat; thus, the decreasing length of stay of all spine fusions may not be consistent with our sample. Nonetheless, for those CP patients in whom surgeons feel a combined ASF/PSF is the best approach, further presurgical planning may be warranted to reduce complications and length of stay, while also providing higher quality of care. The use of a team approach with other specialists may be advantageous in ensuring patients are as prepared for surgery as possible; this will hopefully lead to improved clinical outcomes postoperatively.

This study must be evaluated with the limitations of our work taken into account. Our analyses rely on the accuracy and completeness of the NIS, an administrative database. Prior research comparing NIS with another large database - the American College of Surgeons' National Surgical Quality Improvement Program (ACS NSQIP) - showed that NIS has a higher complication rates. ${ }^{23}$ Additional work specifically in orthopedic surgery has also found differences between a number of large databases. ${ }^{24}$ While no database is perfect, we feel that the use of NIS, based on its design, is more representative of the entire country compared with ACS NSQIP; thus, NIS is an appropriate starting point to get an overarching view of the surgical trends, complications, and charges. Nonetheless, readers should be aware that there are differences between many of the large databases used for similar analyses. In addition, given the nature of 
the NIS database, the severity of CP cannot be captured, and further treatments patients may have received for their $\mathrm{CP}$ also cannot be accounted for in the analyses. In addition, specific patient characteristics related directly to the spine (eg, severity of spinal curvature) is not available in NIS. Nevertheless, we feel this work is a valuable step in better understanding overall surgical spine fusion trends, postoperative complications, length of stay, and charges in this niche patient population across all age ranges. Future work can address whether more specific CP interventions or patient characteristics uncaptured in NIS alter surgical outcomes. Lastly, the database is not granular enough to differentiate the type of instrumentation used for PSF. There is an argument to be made to avoid all pedicle screw instrumentation and use lower profile or inexpensive sublaminar wires or bands, or hybrid constructs of screws, hooks, and sublaminar wires in the setting of neuromuscular scoliosis as seen in $\mathrm{CP} .{ }^{25-27}$

Currently, there is a scarcity of literature analyzing the surgical spine care for patients with $\mathrm{CP}$ and spinal deformity. This nationwide analysis provides previously unreported insight into surgical trends, as well as complication rates, length of stay, and charges of this patient population. By better understanding the surgical approaches and patient comorbidities associated with increased complications, increased length of stay, and charges, preoperative risk stratification through risk factor optimization and patient selection may decrease negative outcomes. Confirmation of our findings with a prospective, multi-center study would further add value to the literature.

\section{REFERENCES}

1. Reames DL, Smith JS, Fu KM, et al. Complications in the surgical treatment of 19,360 cases of pediatric scoliosis: a review of the Scoliosis Research Society Morbidity and Mortality database. Spine. 2011;36(18):1484-1491.

2. Jain A, Njoku DB, Sponseller PD. Does patient diagnosis predict blood loss during posterior spinal fusion in children? Spine. 2012;37(19):1683-1687.

3. Sponseller PD, Jain A, Shah SA, et al. Deep wound infections after spinal fusion in children with cerebral palsy: a prospective cohort study. Spine. 2013;38(23):2023-2027.

4. Menga EN, Hirschfeld C, Jain A, et al. intraoperative cardiopulmonary arrest in children undergoing spinal deformity correction: causes and associated factors. Spine. 2015;40(22):1757-1762.

5. Murphy NA, Firth S, Jorgensen T, Young PC. Spinal surgery in children with idiopathic and neuromuscular scoliosis. What's the difference? J Pediatr Orthop. 2006;26(2):216-220.

6. Yoshihara H, Yoneoka D. National trends in spinal fusion for pediatric patients with idiopathic scoliosis: demographics, blood transfusions, and in-hospital outcomes. Spine. 2014;39(14):1144-1150.

7. Sarwahi V, Sarwark JF, Schafer MF, et al. Standards in anterior spine surgery in pediatric patients with neuromuscular scoliosis. J Pediatr Orthop. 2001;21(6):756-760.

8. Modi HN, Suh SW, Song HR, Fernandez HM, Yang JH. Treatment of neuromuscular scoliosis with posterior-only pedicle screw fixation. J Orthop Surg Res. 2008;3:23.

9. Tsirikos AI, Mains E. Surgical correction of spinal deformity in patients with cerebral palsy using pedicle screw instrumentation. J Spinal Disord Tech. 2012;25(7):401-408.

10. Modi HN, Hong JY, Mehta SS, et al. Surgical correction and fusion using posterior-only pedicle screw construct for neuropathic scoliosis in patients with cerebral palsy: a threeyear follow-up study. Spine. 2009;34(11):1167-1175.

11. Ferguson RL, Hansen MM, Nicholas DA, Allen BL, Jr. Same-day versus staged anterior-posterior spinal surgery in a neuromuscular scoliosis population: the evaluation of medical complications. J Pediatr Orthop. 1996;16(3):293-303.

12. Floman Y, Micheli LJ, Penny JN, Riseborough EJ, Hall JE. Combined anterior and posterior fusion in seventy-three spinally deformed patients: indications, results and complications. Clin Orthop Relat Res. 1982(164):110-122.

13. Shufflebarger HL, Grimm JO, Bui V, Thomson JD. Anterior and posterior spinal fusion. Staged versus same-day surgery. Spine. 1991;16(8):930-933.

14. Swank SM, Cohen DS, Brown JC. Spine fusion in cerebral palsy with L-rod segmental spinal instrumentation. A comparison of single and two-stage combined approach with Zielke instrumentation. Spine. 1989;14(7):750-759.

15. Kuklo TR, Lehman RA Jr, Lenke LG. Structures at risk following anterior instrumented spinal fusion for thoracic adolescent idiopathic scoliosis. J Spinal Disord Tech. 2005;18(suppl):S58-S64.

16. Agency for Healthcare Research and Quality. Overview of the National (Nationwide) Inpatient Sample (NIS). https:// www.hcup-us.ahrq.gov/nisoverview.jsp. Accessed May 1, 2018.

17. Centers for Medicare \& Medicaid Services. List of MSDRGs version 28.0. https://www.cms.gov/icd10manual/full code_cms/P0368.html. Accessed May 1, 2018.

18. United States Census Bureau. Population and housing unit estimates. https://www.census.gov/programs-surveys/pop est.html. Accessed November 1, 2018.

19. Toll BJ, Samdani AF, Janjua MB, Gandhi S, Pahys JM, Hwang SW. Perioperative complications and risk factors in neuromuscular scoliosis surgery. $J$ Neurosurg Pediatr. 2018;22(2):207-213.

20. Master DL, Son-Hing JP, Poe-Kochert C, Armstrong DG, Thompson GH. Risk factors for major complications after surgery for neuromuscular scoliosis. Spine. 2011;36(7):564-571.

21. Bendon AA, George KA, Patel D. Perioperative complications and outcomes in children with cerebral palsy undergoing scoliosis surgery. Paediatr Anaesth. 2016;26(10):970975.

22. Benson ER, Thomson JD, Smith BG, Banta JV. Results and morbidity in a consecutive series of patients undergoing spinal fusion for neuromuscular scoliosis. Spine. 1998;23(21):2308-2317; discussion 2318.

23. Weiss A, Anderson JE, Chang DC. Comparing the National Surgical Quality Improvement Program with the 
Nationwide Inpatient Sample Database. JAMA Surg. 2015;150(8):815-816.

24. Bedard NA, Pugely AJ, McHugh MA, Lux NR, Bozic KJ, Callaghan JJ. Big data and total hip arthroplasty: how do large databases compare? J Arthropl. 2018;33(1):41-45.e43.

25. Desai SK, Sayama C, Vener D, et al. The feasibility and safety of using sublaminar polyester bands in hybrid spinal constructs in children and transitional adults for neuromuscular scoliosis. J Neurosurg Pediatr. 2015;15(3):328-337.

26. La Rosa G, Giglio G, Oggiano L. Surgical treatment of neurological scoliosis using hybrid construct (lumbar transpedicular screws plus thoracic sublaminar acrylic loops). Eur SpineJ. 2011;20(suppl 1):S90-S94.

27. Hasler CC. Operative treatment for spinal deformities in cerebral palsy. Journal of children's orthopaedics. 2013;7(5):419423.

Disclosures and COI: This study did not receive any specific grant from funding agencies in the public, commercial, or not-for-profit sectors. Dr Menga reports consulting for Evolution Spine and being Speaker Honoraria for Globus Medical, outside the submitted work. Mr Bernstein has nothing to disclose. Dr Thirukumaran has nothing to disclose. Dr McCormick has nothing to disclose. Dr Rubery reports grants from AOSpine. Dr Mesfin reports grants from LES Society, grants from Corelink, grants from AOSpine, grants from OMeGA, grants from Globus, outside the submitted work.

Corresponding Author: Addisu Mesfin, MD, University of Rochester School of Medicine and Dentistry, 601 Elmwood Ave, Box 665, Rochester, NY 14642. Phone: (585) 275-5196; Fax: (585) 7564726; Email: amesfin@gmail.com.

Published 30 June 2020

This manuscript is generously published free of charge by ISASS, the International Society for the Advancement of Spine Surgery. Copyright (c) 2020 ISASS. To see more or order reprints or permissions, see http://ijssurgery.com. 